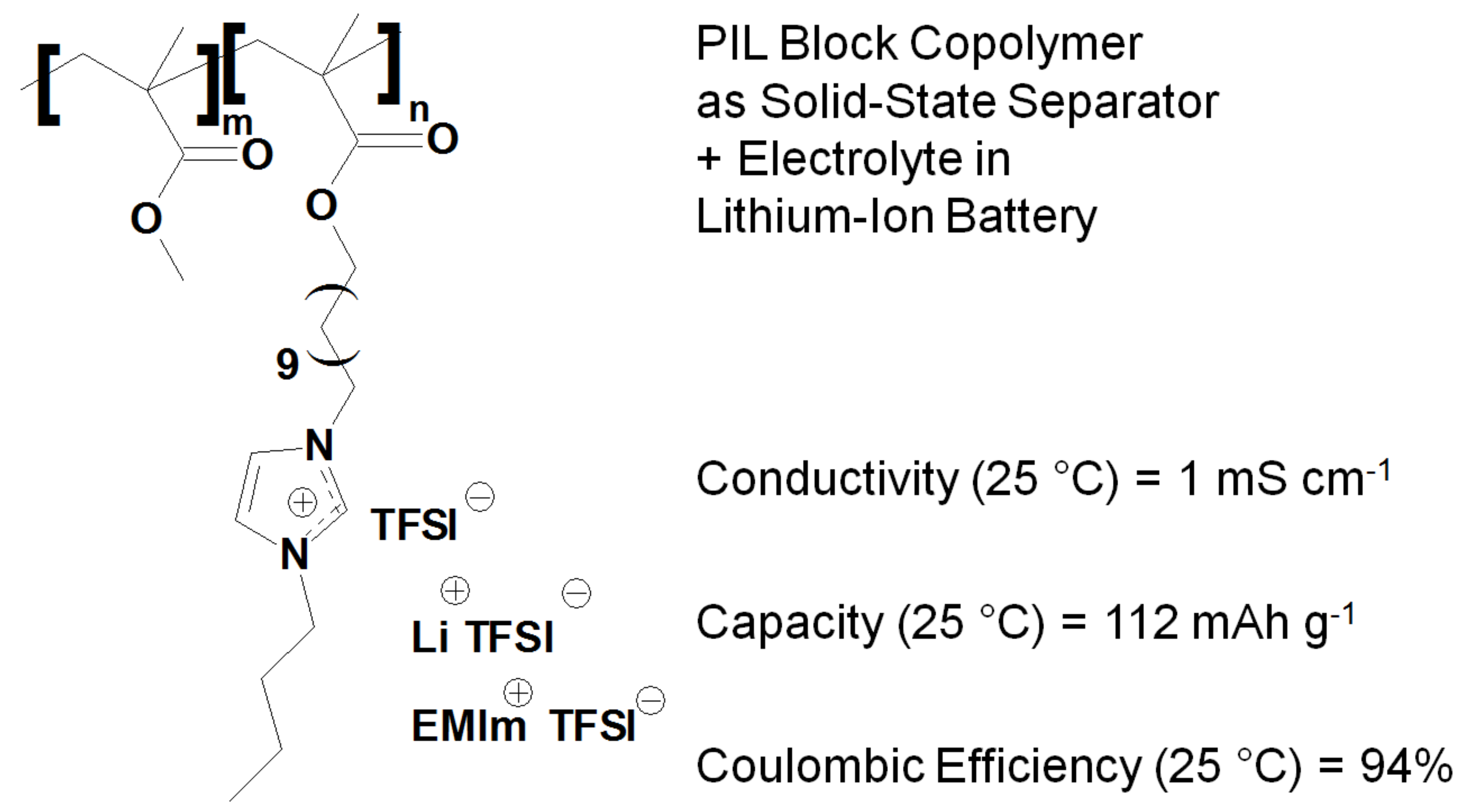




\section{Polymerized Ionic Liquid Diblock Copolymer as Solid-State Electrolyte and Separator in Lithium-Ion Battery}

Jacob R. Nykaza, ${ }^{1}$ Alice M. Savage, ${ }^{2}$ Qiwei Pan, ${ }^{3}$ Shijun Wang, ${ }^{3}$ Frederick L. Beyer, ${ }^{2}$ Maureen H. Tang, ${ }^{1}$ Christopher Y. Li, ${ }^{3}$ and Yossef A. Elabd ${ }^{4, Z}$

${ }^{1}$ Department of Chemical and Biological Engineering, Drexel University, Philadelphia, Pennsylvania 19104, United States

${ }^{2}$ Army Research Laboratory, Aberdeen Proving Ground, Maryland 21005, United States ${ }^{3}$ Department of Material Science and Engineering, Drexel University, Philadelphia, Pennsylvania, 19014, United States

${ }^{4}$ Department of Chemical Engineering, Texas A\&M University, College Station, Texas 77843, United States

z E-mail: elabd@tamu.edu 


\begin{abstract}
A polymerized ionic liquid diblock copolymer (PILBCP-TFSI), poly(MMA- $b$-MUBIm-TFSI), consisting of an ionic liquid monomer, (1-[(2-methacryloyloxy)undecyl]-3-butylimidazolium bis(trifluoromethane)sulfonamide) (MUBIm-TFSI), and a non-ionic monomer, methyl methacrylate (MMA), was synthesized via reverse addition fragmentation chain transfer polymerization followed by anion exchange metathesis. Free standing, mechanically stable transparent solid polymer films were produced with PILBCP-TFSI containing $1 \mathrm{M}$ lithium bis(trifluoromethane)sulfonamide in 1-ethyl-3-methylimidazolium bis(trifluoromethylsulfonyl)imide (Li-TFSI/EMIm-TFSI). The resulting PILBCP-TFSI + LiTFSI/EMIm-TFSI films possessed ion conductivities from 1 to $10 \mathrm{mS} \mathrm{cm}^{-1}$ from $25{ }^{\circ} \mathrm{C}$ to 105 ${ }^{\circ} \mathrm{C}$. Solid-state lithium-ion coin cell batteries were assembled and tested at room temperature with PILBCP-TFSI + Li-TFSI/EMIm-TFSI films as the solid-state electrolyte and separator and resulted in a maximum discharge capacity of $112 \mathrm{mAh} \mathrm{g}^{-1}$ at $0.1 \mathrm{C}$ with a Coulombic efficiency greater than $94 \%$ over 100 cycles. For the first time, these results demonstrate the feasibility of PIL block copolymers as solid-state electrolytes and separators in lithium-ion batteries.
\end{abstract}

Keywords: ionic liquid; block copolymer; membrane 


\section{Introduction}

Recently, solid polymer electrolytes (SPEs) have been explored as solid-state ion conducting electrolytes and separators in lithium-ion batteries due to their improved flammability safety compared to traditional liquid electrolytes.[1-3] Other advantages include suppression of dendrite growth, better shape flexibility, and improved electrochemical stability when compared to typical liquid electrolytes.[4] One primary drawback to SPEs is the relatively low ionic conductivity, specifically at room temperature, where traditionally the ionic conductivity must be on the order of $1 \mathrm{mS} \mathrm{cm}{ }^{-1}$ or higher for practical battery applications.[5] Many SPEs currently fail to meet this conductivity criterion, which prevents their commercialization. The ideal SPE for an all solid-state battery would have the high room temperature ionic conductivity of a liquid (for high overall storage capacity, energy and power), the mechanical properties of a solid (for improved stability and cyclability), and the formability of a thermoplastic (for good processability and flexibility).

Polymerized ionic liquids (PILs), a new class of polymer electrolyte (a polymeric form of ionic liquids (ILs)), have recently been explored as SPEs for electrolytes and separators in solid-state lithium-ion batteries.[6, 7] PILs possess unique properties, such as high solid-state ionic conductivity, high chemical, electrochemical, and thermal stability, and a widely tunable chemical platform, where significant changes in physical properties have been observed with subtle changes in chemistry.[8-10] PILs and their corresponding ILs have strong affinity for one another, compared to other polymers, which allows for complete compatibility or miscibility.[11] The use of ILs within PIL-based SPEs is known to be stable, which minimizes phase separation and IL leakage. The use of ILs as electrolytes in lithium-ion batteries has been well documented 
in the literature, where the benefits over traditional liquid electrolytes include non-flammability and non-volatility, as well as having similar properties as PILs as described above.[12-14] One should note that in many of these previous reports for lithium-ion battery applications, a source of lithium ions is typically a lithium salt (e.g., lithium bis(trifluoromethanesulfonyl)imide (LiTFSI)) dissolved in an IL.[6]

To date, there are only a few reports of PILs as solid-state electrolytes and separators in batteries, where the PIL SPE typically consists of a mixture of lithium salt and IL imbibed in the film.[6, 15-19] Most of these studies have examined PIL homopolymers, where an IL monomer is polymerized using free-radical polymerization to produce a PIL as the SPE. Appetecchi et al.[17] synthesized a poly(diallyldimethylammonium) bis(trifluoromethanesulfonyl)imide PIL and incorporated the PYR 14 -TFSI IL with Li-TFSI salt within the SPE. The PIL with $60 \mathrm{wt} \%$ $\mathrm{IL} / \mathrm{salt}$ had a conductivity of $0.5 \mathrm{mS} \mathrm{cm}{ }^{-1}$ at $40{ }^{\circ} \mathrm{C}$ and a $\mathrm{Li} / \mathrm{LiFePO}_{4}$ solid-state battery capacity of $82.3 \%$ of the theoretical capacity at $40{ }^{\circ} \mathrm{C}$. Sato et al.[18] synthesized an ammonium-based PIL, poly(N,N-diethyl-N-(2-methacryloylethyl)-N-methylammonium bis(trifluoromethylsulfonyl)imide) (poly(DEMM-TFSI)), and added a mixture of DEMETFSI/Li-TFSI and achieved a discharge capacity of $97.7 \%$ of the theoretical capacity and a $97 \%$ Coulombic efficiency at $40{ }^{\circ} \mathrm{C}$ with this PIL + IL/salt as the electrolyte and separator in a battery using $\mathrm{Li}_{4} \mathrm{Ti}_{5} \mathrm{O}_{12}$ and $\mathrm{LiMn}_{2} \mathrm{O}_{4}$ as the anode and cathode, respectively. However, the use of homopolymers can lead to battery failure over time due to the low mechanical properties of some homopolymers. Li et al.[15] copolymerized a guanidinium-based IL monomer with methyl acrylate to form a random copolymer. This PIL random copolymer acted as a host for a guanidinium-based IL, Li-TFSI salt, and nano-sized $\mathrm{SiO}_{2}$ and was incorporated as the solid-state electrolyte and separator in $\mathrm{Li} / \mathrm{LiFePO}_{4}$ batteries. This SPE had a relatively low ionic 
conductivity of $0.117 \mathrm{mS} \mathrm{cm}^{-1}$ even at a high temperature of $80{ }^{\circ} \mathrm{C}$. Therefore, batteries tests were conducted at this high temperature of $80{ }^{\circ} \mathrm{C}$ with a discharge capacity of $93 \%$ of the theoretical capacity and capacity fade of $0.27 \mathrm{mAh} \mathrm{g}^{-1}$ per cycle.

The use of block copolymers, instead of random copolymers, can assist in improving properties and can potentially provide the desired orthogonal properties of high ion conduction and high mechanical strength in the solid-state and have been explored for battery applications.[20-24] One recent example includes work by Bouchet et al.[25] in which they synthesized a single-ion conductor triblock copolymer with a conductivity of $0.013 \mathrm{mS} \mathrm{cm}-1$ at $60{ }^{\circ} \mathrm{C}$ and a discharge capacity of $>88 \%$ of the theoretical capacity at $60{ }^{\circ} \mathrm{C}$ with lithium metal anodes and $\mathrm{LiFePO}_{4}$ cathodes.

PIL block copolymers (PILBCPs) are a new distinct class of block copolymer that combines the properties of PILs and block copolymers, where the latter is known to self-assemble into a variety of different nanostructures (e.g., body centered cubic spheres, hexagonal packed cylinders, and lamellae).[11] A recent report has shown that when PILs self-assemble into continuous ion-rich microdomains within block copolymer morphologies, accelerated ion transport within these continuous nanostructured ion-channels can occur.[9] Ye et al.[10] compared a single-ion conductor PIL block copolymer to its analogous PIL random copolymer at the same PIL composition and showed that the ionic conductivity of the block copolymer was 2 orders of magnitude higher than the random copolymer, which was due to the microphase separated morphology in the block copolymer. Although there are now a number of recent studies on the conductivity and morphology of PILBCPs[11, 26-31], there are few that examine the conductivity of lithium ions in PILBCPs. Recent work by Wang et al.[7] reports on the ionic conductivity $\left(0.47 \mathrm{mS} \mathrm{cm}^{-1}\right.$ at $\left.100{ }^{\circ} \mathrm{C}\right)$ and electrochemical stability of $\left(4.2 \mathrm{~V}\right.$ versus $\left.\mathrm{Li} / \mathrm{Li}^{+}\right)$of a 
PILBCP with additional PIL (50.7 mol\%) and Li-TFSI (5 wt $\%$ ). However, they did not report on battery performance for this PILBCP. To date, there are no reports of a PILBCP as the electrolyte and separator in a lithium-ion battery.

In this work, a PIL diblock copolymer, poly(MMA-b-MUBIm-Br) (denoted as PILBCP-Br), was synthesized via the reverse addition fragmentation chain transfer (RAFT) polymerization technique at a single composition (20.0 mol\% PIL) and then was subsequently ion exchanged to the bis(trifluoromethane)sulfonamide (TFSI ${ }^{-}$) form, poly(MMA- $b$-MUBIm-TFSI) (denoted as PILBCP-TFSI). PILBCP-TFSI was then imbibed with a $1.0 \mathrm{M}$ solution of LiTFSI in EMImTFSI (denoted as Li-TFSI/EMIm-TFSI) to produce the lithium-conducting PILBCP SPE (denoted as PILBCP-TFSI + LiTFSI/EMIm-TFSI). The glass transition temperatures, thermal degradation temperature, and ionic conductivity of the new PILBCP-TFSI and PILBCP-TFSI + LiTFSI/EMIm-TFSI SPEs were measured. The morphology was invested using small angle Xray scattering (SAXS) and transmission electron microscopy (TEM). The electrochemical stability and lithium-ion battery performance of PILBCP-TFSI + LiTFSI/EMIm-TFSI as the solid-state electrolyte and separator were investigated. To our knowledge, this is the first report of lithium-ion battery performance of a PIL block copolymer.

\section{Experimental}

\subsection{Materials}

Acetonitrile (anhydrous, 99.8\%), bis(trifluoromethane)sulfonamide lithium salt (Li-TFSI, 99.95\%), 1-methyl-2-pyrrolidinone (NMP; anhydrous, 99.5\%), platinum foil (Pt; 0.125-0.135 mm, 99.99\%), and silver foil (Ag; $0.5 \mathrm{~mm}, 99.99 \%)$ were used as received from Sigma-Aldrich. 1-ethyl-3-methylimidazolium bis(trifluoromethylsulfonyl)imide (EMIm-TFSI, >99\%) was used 
as received from Iolitec. Lithium titanate $\left(\mathrm{Li}_{4} \mathrm{Ti}_{5} \mathrm{O}_{12} ;>98 \%\right)$, conductive graphite $(\geq 99.98 \%)$, polyvinylidene fluoride (PVDF; $\geq 99.5)$, and lithium cobalt oxide $\left(\mathrm{LiCoO}_{2}\right)$ pre-coated $\mathrm{Al}$ current collector (single sided) were used after drying at $100{ }^{\circ} \mathrm{C}$ under vacuum for $12 \mathrm{~h}$ from MTI Corporation. CR2032 Coin Cell Cases $(20 \mathrm{~mm} \mathrm{D} \times 3.2 \mathrm{~mm} \mathrm{~T})$ with O-rings for battery research, stainless steel spacer for CR2032 Cell $(15.5 \mathrm{~mm} \mathrm{D} \times 0.5 \mathrm{~mm} \mathrm{~T})$, stainless steel wave spring for CR2032 Case were used as received from MTI Corporation. Ultrapure deionized (DI) water with resistivity $\approx 16 \mathrm{M} \Omega \mathrm{cm}$ was used as appropriate. The polymerized ionic liquid (PIL) diblock copolymer, PILBCP-TFSI, was synthesized by anion exchange from its precursor form, PILBCP-Br, which was prepared according to literature and is described below.[32, 33]

\subsection{Synthesis of PIL diblock copolymer: PILBCP-TFSI}

Imidazolium-based PIL diblock copolymer, poly(methyl methacrylate-block-1-[(2methacryloyloxy)undecyl]-3-bromide (referred to as PILBCP-Br), was used as the precursor polymer in this study (left structure in Scheme 1) and was synthesized previously from an ionic liquid monomer, 1-[(2-methacryloyloxy)undecyl]-3-butylimidazolium bromide (MUBIm-Br), and a non-ionic monomer, methyl methacrylate (MMA), via the reverse addition fragmentation chain transfer (RAFT) polymerization technique.[32, 33] Herein, this PIL block copolymer is reported at a single PIL composition of $20.0 \mathrm{~mol} \%$, in which its synthesis and characterization were previously described in detail in literature.[33] The bis(trifluoromethylsulfonyl)imide (TFSI $\left.{ }^{-}\right)$-exchanged PIL diblock copolymer, PILBCP-TFSI $\left(\mathrm{M}_{\mathrm{n}}=40.6 \mathrm{~kg} / \mathrm{mol}\right)$, used in this study, was prepared via ion exchange metathesis of the precursor PIL diblock copolymers, PILBCP-Br, as shown in Scheme 1. This exchange was performed in the solid state (films; see section below for details on film casting procedure). Scheme 1 provides details of the ion 
exchange metathesis, where films were placed in a well-mixed $0.1 \mathrm{M} \mathrm{Li-TFSI}$ aqueous solution for $12 \mathrm{~h}$. The Li-TFSI solution was replaced with a freshly prepared solution every $4 \mathrm{~h}$ and repeated 3 times. The TFSI--exchanged films were then soaked in fresh DI water for $30 \mathrm{~min}$ and repeated 3 times to remove excess $\mathrm{TFSI}^{-}$anions. Residual water was removed by drying under vacuum at room temperature for $24 \mathrm{~h}$. Figure 1a shows a picture of a solid-state film of PILBCPTFSI after anion exchange metathesis. Elemental Analysis (EA) Calcd: C, 51.1; H, 6.9; N, 3.8; F, 10.4; S, 5.8; Br, 0.0. Found: C, 51.9; H, 7.4; N, 4.9; F, 8.6; S, 5.0; Br, 0.0.

Scheme 1. Synthesis of PILBCP-TFSI + Li-TFSI/EMIm-TFSI.
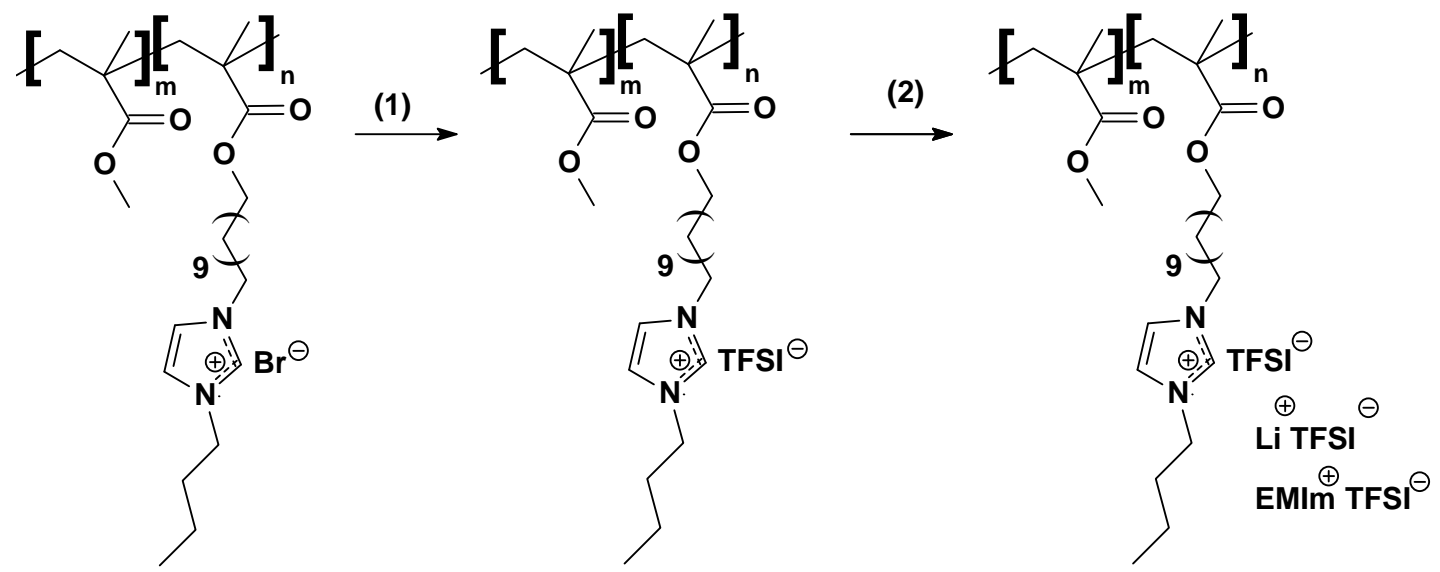

(1) $0.1 \mathrm{M} \mathrm{Li}$-TFSI in $\mathrm{H}_{2} \mathrm{O}$, room temp., $24 \mathrm{~h}$; (2) $1.0 \mathrm{M}$ Li-TFSI in EMIm-TFSI, room temp., 8h.

\subsection{Solvent casting of PIL block copolymer films}

Films of the precursor PIL block copolymer, PILBCP-Br, were fabricated by first dissolving the polymer in anhydrous acetonitrile $(4 \mathrm{wt} \% \mathrm{w} / \mathrm{w})$ and subsequently casting onto Teflon substrates $(c a .18 \mathrm{~mm}(D) \times 0.525(T))$ for lithium-ion battery experiments and Teflon substrates $($ ca. $35 \mathrm{~mm}(\mathrm{~L}) \times 4 \mathrm{~mm}(\mathrm{~W}) \times 0.525 \mathrm{~mm}(\mathrm{~T}))$ for thermal experiments. Polymer solutions were partially covered and allowed to evaporate under ambient conditions for $24 \mathrm{~h}$. The polymer films were subsequently annealed under vacuum at $150{ }^{\circ} \mathrm{C}$ for $72 \mathrm{~h}$. These annealed films were anion exchanged to the TFSI $^{-}$form, PILBCP-TFSI, according to the procedure described above. The 
film thicknesses, ranging from 35 to $100 \mu \mathrm{m}$, were measured with a Mitutoyo digital micrometer $( \pm 0.001 \mathrm{~mm}$ accuracy). PIL block copolymer film appears translucent in Figure 1a due to the surface effects of casting on milled Teflon substrates. No large-scale phase separation was observed with optical microscopy. Clear films were produce when cast on glass slides, but Teflon substrates were used for easy removal to produce free-standing films.

\subsection{Preparation of PILBCP-TFSI + Li-TFSI/EMIm-TFSI solid-state films}

The dried films of PILBCP-TFSI were then immersed in a 1.0 M Li-TFSI in EMIm-TFSI (LiTFSI/EMIm-TFSI) solution for $12 \mathrm{~h}$ at room temperature (see Scheme 1(2)). The resulting film, PILBCP-TFSI + Li-TFSI/EMIm-TFSI, was removed from the Li-TFSI/EMIm-TFSI solution and excess Li-TFSI/EMIm-TFSI was removed from the surface using a lint-free cloth. Films were then dried under vacuum at room temperature for $24 \mathrm{~h}$ before use. The final film contained on average $67 \pm 5 \mathrm{wt} \% \mathrm{Li}-\mathrm{TFSI} / \mathrm{EMIm}-\mathrm{TFSI}$ and is shown in Figure $1 \mathrm{~b}$.

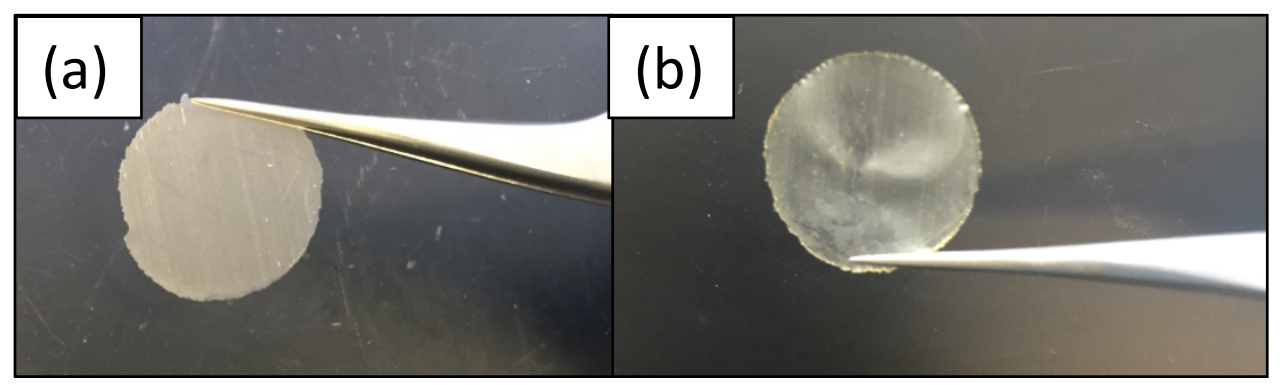

Figure 1. Image of $\sim 50 \mu \mathrm{m}$ thick of (a) PILBCP-TFSI and (b) PILBCP-TFSI + Li-TFSI/EMImTFSI solid-state films.

\subsection{Preparation of lithium-ion batteries with PILBCP-TFSI + Li-TFSI/EMIm-TFSI film as solid-} state electrolyte and separator

$\mathrm{Al}$ current collector coated (single sided) with lithium cobalt oxide $\left(\mathrm{LiCoO}_{2}\right)$ was used as the positive electrode (cathode). Loading of the active material was approximately $12.8 \mathrm{mg} \mathrm{cm}^{-2}$ 
corresponding to theoretical capacity of $1.86 \mathrm{mAh} \mathrm{cm}^{-2}$. The negative electrode (anode) was prepared by spreading a mixture of $\mathrm{Li}_{4} \mathrm{Ti}_{5} \mathrm{O}_{12}$, conductive graphite, and PVDF with a weight ratio of 8:1:1 dissolved in NMP onto a $\mathrm{Cu}$ current collector using an adjustable film applicator (MTI Corp.). The film thicknesses, ranging from 20 to $30 \mu \mathrm{m}$, were measured with a Mitutoyo digital micrometer ( $\pm 0.001 \mathrm{~mm}$ accuracy). The cathode was allowed to dry overnight and then placed under vacuum at $80{ }^{\circ} \mathrm{C}$ for $2 \mathrm{~h}$ before use. Loading of the active material was approximately $0.64 \mathrm{mg} \mathrm{cm}^{-2}$ corresponding to theoretical capacity of $0.10 \mathrm{mAh} \mathrm{cm}{ }^{-2}$ and the electrode was used without any additional preparation or pressing. The anode was the limiting electrode (theoretical capacities: cathode $=1.86 \mathrm{mAh} \mathrm{cm}^{-2}$, anode $=0.10 \mathrm{mAh} \mathrm{cm}^{-2}$ ). $\mathrm{Li}_{4} \mathrm{Ti}_{5} \mathrm{O}_{12} / \mathrm{LiCoO}_{2}$ polymer batteries were fabricated in an argon-purged glove box (MBraun LABstar, $\mathrm{H}_{2} \mathrm{O}<0.7 \mathrm{ppm}$ ) by laminating the $\mathrm{LiCoO}_{2}$ positive electrode with a $c a .50 \mu \mathrm{m}$ film of PILBCP-TFSI + Li-TFSI/EMIm-TFSI and then adding the $\mathrm{Li}_{4} \mathrm{Ti}_{5} \mathrm{O}_{12}$ negative electrode as shown in Figure 2. Cells were pressed twice using an electric coin cell crimping machine (MTI Corp., MSK-160D) under argon environment at room temperature to ensure a proper seal was established. Additional Li-TFSI/EMIm-TFSI $(\sim 5 \mu \mathrm{L})$ was added to each electrode during assembly to ensure there was a sufficient amount dispersed throughout the electrodes and in the cell. Assembled cells were held at open circuit voltage (OCV) for $12 \mathrm{~h}$ prior to testing to ensure even distribution of Li-TFSI/EMIm-TFSI throughout the electrodes. 


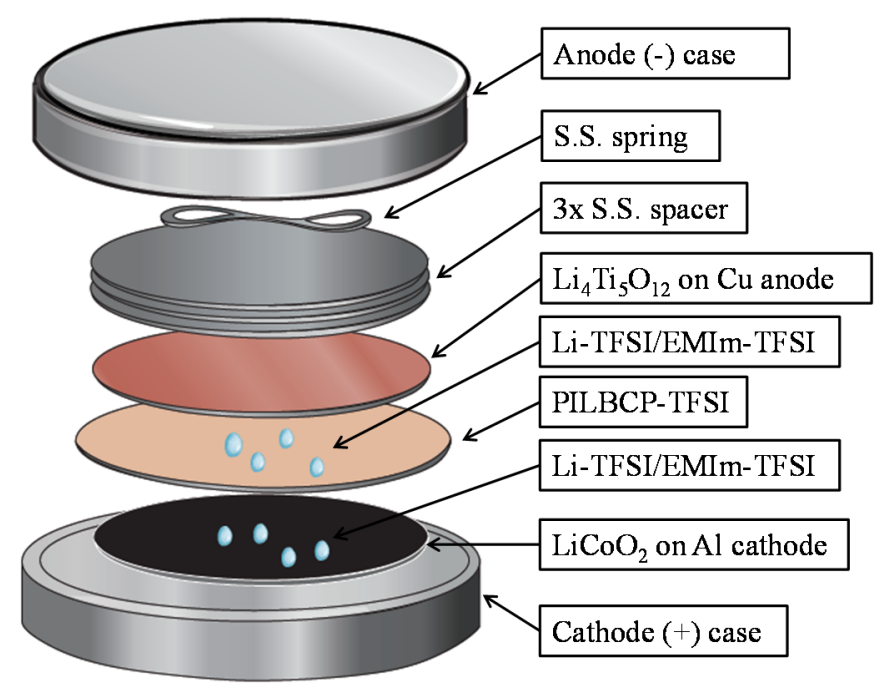

Figure 2. Schematic showing configuration of lithium-ion coin cell battery with PILBCP-TFSI + Li-TFSI/EMIm-TFSI as solid-state separator.

\subsection{Characterization}

Polymer films were characterized using an FTIR-ATR spectrometer (Nicolet 6700 Series, Thermo Electron Corporation) with spectra collected using the single reflection diamond ATR Golden Gate ${ }^{\mathrm{TM}}$ accessory. All infrared spectra were collected using a liquid nitrogen-cooled mercury-cadmium-telluride detector at 32 scans per spectrum and a resolution of 4 and data spacing less than $2 \mathrm{~cm}^{-1}$. All spectra were corrected with a background subtraction of the ATR crystal spectrum. Glass transition temperatures $\left(T_{\mathrm{gs}}\right)$ were determined by differential scanning calorimetry (DSC; TA instruments Q200) over a temperature range of -115 to $150{ }^{\circ} \mathrm{C}$ at a heating/cooling rate of $10{ }^{\circ} \mathrm{C} / \mathrm{min}$ under a $\mathrm{N}_{2}$ environment using a heat/cool/heat method. $T_{\mathrm{g}}$ was determined using the midpoint method from the second thermogram heating cycle. Thermal degradation temperatures $\left(T_{\mathrm{d}}\right)$ were measured by thermal gravimetric analysis (TGA; TA Instruments, Q50) over a temperature range of 30 to $500{ }^{\circ} \mathrm{C}$ at a heating rate of $10{ }^{\circ} \mathrm{C} / \mathrm{min}$ under 
argon environment. $T_{\mathrm{d}}$ was determined at $5 \mathrm{wt} \%$ mass loss in the thermogram. Elemental analysis was performed by Atlantic Microlab, Inc., Nocross, GA.

The ionic conductivities and linear voltammetry of the polymer films were measured in an argon-purged glovebox (MBraun) with custom-made cells using a using a potentiostat/ galvanostat/FRA (Princeton Applied Research, Parstat 2273; POWERSUITE software). In-plane conductivity was measured using a four-parallel-electrode method with two outer working electrodes and two inner sensing electrodes placed on the same side of the sample, where an alternating current was applied to the outer electrodes and the real impedance or resistance, $R$, was measured between the two inner electrodes.[34] The alternating current impedance was collected from $0.1 \mathrm{~Hz}$ to $1 \mathrm{MHz}$ at $500 \mathrm{mV}$. The resistance was determined from the high $x$ intercept of the semi-circle regression of the Nyquist plot. Conductivity was calculated by using the following equation: $\sigma=L / A R$, where $L$ is the distance between two inner electrodes and $A$ is the cross-sectional area of the polymer film or electrolyte $(A=W l ; W$ is the width and $l$ is the thickness). Temperature-dependent ionic conductivity was measured with the use of a Mettler Toledo hot stage with a temperature accuracy of less than $0.1{ }^{\circ} \mathrm{C}$. In the linear voltammetry scan, Ag foil was used as the reference and counter electrodes, and Pt foil was used as the working electrode. The voltage was scanned from -2.4 to $3.3 \mathrm{~V} v s . \mathrm{Ag}^{+} / \mathrm{Ag}$ with a scan rate of $5 \mathrm{mV} \mathrm{s}^{-1}$. The Ag pseudo-reference electrode in EMIm-TFSI has been previously calibrated to $+3.2 \mathrm{~V}$ $\mathrm{Li}^{+} / \mathrm{Li}$ with a butyl-ferrocene/ferricinium redox couple.[35] Therefore, the same value $(+3.2 \mathrm{~V}$ $\mathrm{Li}^{+} / \mathrm{Li}$ ) was used to reference $\mathrm{Ag}$ to $\mathrm{Li}^{+} / \mathrm{Li}$ in this work. Cycling tests on $\mathrm{Li}_{4} \mathrm{Ti}_{5} \mathrm{O}_{12} / \mathrm{LiCoO}_{2}$ coin cell polymer batteries were performed at room temperature using a MACCOR S4000 battery tester. The discharge and charge rates were fixed at a $\mathrm{C} / 10\left(0.014 \mathrm{~mA} \mathrm{~cm}^{-2}\right)$ current rate. The charge and discharge voltage cut-offs were fixed at $2.5 \mathrm{~V}$ and $2.0 \mathrm{~V}$, respectively. 
Small-angle X-ray scattering (SAXS) data was collected at the U.S. Army Research Laboratory using a 2-D multi-wire area detector (Molecular Metrology) and a $3 \mathrm{~m}$, pinholecollimated camera. Photons, with a wavelength of $1.54 \AA$, were generated, using an Ultrax 18 rotating copper anode X-ray generator (Rigaku Americas, Inc.), operated at $4.5 \mathrm{~kW}$ and equipped with a Ni filter. 2-D data were collected at sample-to-detector distances of 1.5 and $0.5 \mathrm{~m}$, and then azimuthally averaged to yield intensity, $\mathrm{I}(q)$, as a function of scattering vector magnitude, $q$, where $q=4 \pi \sin (\theta) / \lambda, 2 \theta$ is the scattering angle, and $\lambda$ is wavelength. Distance calibrations were performed using silver behenate.[36] The data were corrected for background noise and scaled to absolute intensity using glassy carbon, previously calibrated at the Advanced Photon Source, Argonne National Laboratory, as a secondary standard.[37] All data manipulation and analysis were performed using Igor Pro (Wavemetrics, Inc.).[38] Samples were prepared for transmission electron microscopy (TEM) by ultracryomicrotomy (Leica UCT) equipped with a cryogenic cooling stage. Samples were cut in sections of approximately $90 \mathrm{~nm}$ thick using a Microstar diamond knife and were cooled to $-10{ }^{\circ} \mathrm{C}$ prior to sectioning. A JEOL JEM-2100F TEM and a Gatan 806 high-angle annular dark field scanning TEM (HAADF STEM) detector were used to collect dark field data. The TEM was operated at $200 \mathrm{keV}$, with a $40 \mu \mathrm{m}$ condenser aperture, a HAADF STEM collection angle of 48 to $168 \mathrm{mrad}$, and spot size of $0.2 \mathrm{~nm}$. A Gatan Digital Micrograph was used to collect and analyze the data. In dark field images, high $\mathrm{Z}$ regions appear bright and low $\mathrm{Z}$ regions appear dark. 


\section{Results and Discussion}

\subsection{Chemical and Thermal Properties}

The synthesis of the PIL block copolymer, PILBCP-TFSI, as shown in Scheme 1, was achieved via anion exchange metathesis, which converts the polymer to bis(trifluoromethane)sulfonamide (TFSI ${ }^{-}$) form. Previously, PILs that are exchanged with TFSI anions exhibit high hydrophobicity and high ionic conductivity (due to low glass transition temperatures), which are both important for lithium-ion battery applications.[39] Elemental analysis results quantitatively confirm a complete anion exchange of the polymer from $\mathrm{Br}^{-}$to TFSI $^{-}$form, where no measureable bromide was present in the PILBCP-TFSI sample. FTIRATR spectra also confirm anion exchange (shown in Figure 3). The anion exchange reaction was confirmed by the observance of three additional characteristic infrared bands at 13501134 , and $1055 \mathrm{~cm}^{-1}$, which were due to the contributions of the TFSI- anion and are consistent with literature.[40, 41] The bands at 1350 and $1134 \mathrm{~cm}^{-1}$ correspond to the $\mathrm{SO}_{2}$ antisymmetric and symmetric stretching, respectively, and the band at $1055 \mathrm{~cm}^{-1}$ corresponds to a S-N-S antisymmtetic stretching, $\mathrm{C}-\mathrm{C}$ stretching, and $\mathrm{NCH}_{3}$ twisting. Note that at ambient conditions, there appears to be a small amount of water in the precursor polymer, PILBCP-Br, as evidenced by that $\mathrm{O}-\mathrm{H}$ stretching band at $3407 \mathrm{~cm}^{-1}$. This was expected due to the hydroscopic nature of PILs exchanged with halide counter anions. After anion exchange to the TFSI ${ }^{-}$form, the FTIRATR spectra of PILBCP-TFSI shows no noticeable bands that are associated with water suggesting that there is a negligible amount of water in the sample. 


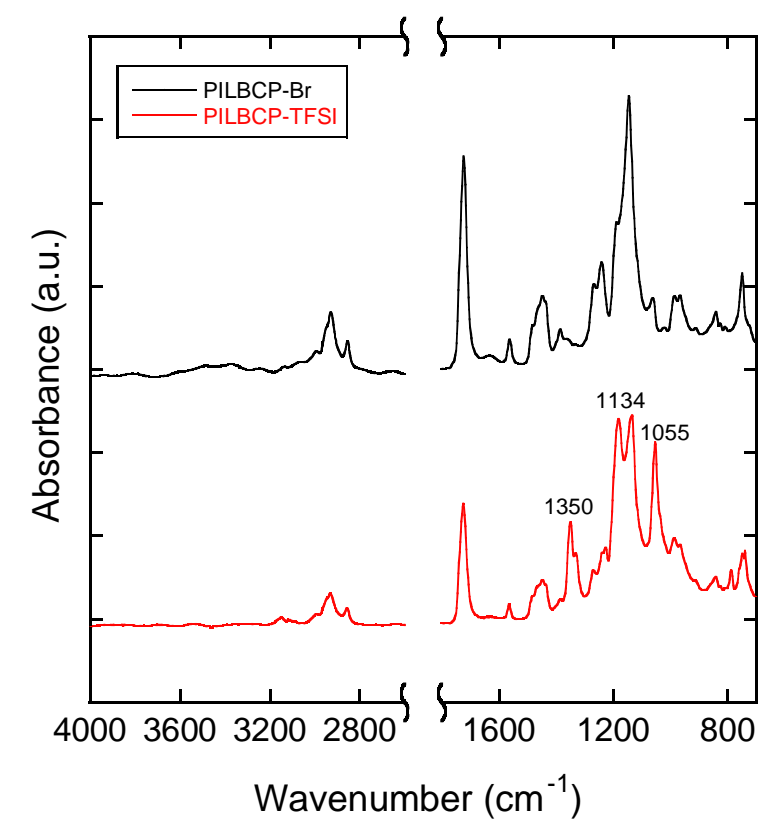

Figure 3. FTIR-ATR spectra of PILBCP-Br (black) and PILBCP-TFSI (red). Spectra offset for clarity.

PILBCP-TFSI was then immersed in a solution of $1.0 \mathrm{M}$ Li-TFSI in EMIm-TFSI (LiTFSI/EMIm-TFSI). The addition of Li-TFSI/EMIm-TFSI to the PILBCP-TFSI solid-state electrolyte can lower the glass transition temperature of the film or act as a plasticizer, thereby improving the ionic conductivity, while also providing a source of $\mathrm{Li}^{+}$ions that are required for $\mathrm{Li}^{+}$-ion batteries. The addition of the Li-TFSI/EMIm-TFSI and its concentration were chosen based on promising room temperature conductivity and $\mathrm{Li}^{+}$-ion battery performance shown by Garcia and coworkers.[35] The resulting films of PILBCP-TFSI + Li-TFSI/EMIm-TFSI, used as solid-state electrolytes and separators in $\mathrm{Li}^{+}$-ion coin cells in this study, contained on average 67 $\pm 5 \mathrm{wt} \%$ of Li-TFSI/EMIm-TFSI imbibed within the PILBCP-TFSI film.

Figure 4a shows the glass transition temperatures $\left(T_{\mathrm{g}} \mathrm{s}\right)$ measured by DSC of the PILBCP-TFSI films with and without Li-TFSI/EMIm-TFSI. Only one distinct $T_{\mathrm{g}}$ was observed for PILBCPTFSI at $29^{\circ} \mathrm{C}$ and after the addition of Li-TFSI/EMIm-TFSI, this $T_{\mathrm{g}}$ is depressed (as predicted) by over $100{ }^{\circ} \mathrm{C}$ to $-84^{\circ} \mathrm{C}$, which is close to the pure component $T_{\mathrm{g}}$ of EMIm-TFSI $\left(-98^{\circ} \mathrm{C}\right)$.[42] It 
is interesting to note that in a previous study the precursor PILBCP-Br has two distinct $T_{\mathrm{gS}}$ at 23 ${ }^{\circ} \mathrm{C}$ and $124{ }^{\circ} \mathrm{C}$, where a $T_{\mathrm{g}}$ at $23{ }^{\circ} \mathrm{C}$ corresponds to the pure PIL, poly(MUBIm-Br), and a $T_{\mathrm{g}}$ at $124{ }^{\circ} \mathrm{C}$ corresponds to the pure poly(MMA).[32] The two $T_{\mathrm{g} s}$ suggests strong microphase separation in PILBCP-Br, which was supported by TEM and SAXS results. The lack of two distinct $T_{\mathrm{g}} \mathrm{S}$ in Figure 4a for PILBCP-TFSI suggests that the anion exchange methathesis from $\mathrm{Br}^{-}$to TFSI ${ }^{-}$may enhance the interaction between the PMMA and PIL blocks.[26, 43] Ye et $a l .[10]$ showed that in a similar PILBCP, poly(MMA-b-MEBIm-TFSI), where the alkyl side chain length between the polymeric backbone and the imidazole moiety in the PIL block is shorter (ethyl compared to undecyl in this study), that the block copolymer still exhibited two $T_{\mathrm{g} S}$ for the PIL and poly(MMA) blocks, but these $T_{\mathrm{g}}$ s deviate from their corresponding homopolymer $T_{\mathrm{gs}}$ suggesting that the PIL, poly(MEBIm-TFSI), is partially miscible with poly(MMA), which was supported by TEM and SAXS results in that study. It is unclear why two $T_{\mathrm{g}} \mathrm{s}$ are not present in the DSC data in this study for PILBCP-TFSI. The DSC data of ion-containing polymers can sometimes be unclear and a more accurate determination of thermal transition temperatures may be observed more clearly by other techniques (e.g., dynamic mechanical analysis).[44]

Figure $4 \mathrm{~b}$ shows the thermal stability of the samples characterized by TGA under an argon environment. The thermal decomposition temperatures $\left(T_{\mathrm{d}} \mathrm{S}\right)$ measured at $5 \mathrm{wt} \%$ loss for PILBCP-TFSI had a slightly lower $T_{\mathrm{d}}\left(319^{\circ} \mathrm{C}\right)$ than PILBCP-TFSI + Li-TFSI/EMIm-TFSI $(350$ $\left.{ }^{\circ} \mathrm{C}\right)$. Both samples undergo a one-step thermal decomposition where this decomposition is similar to the $T_{\mathrm{d}}$ of poly(vinylimidazole) $\left(335^{\circ} \mathrm{C}\right)$.[45] The slight increase in $T_{\mathrm{d}}$ with the addition of Li-TFSI/EMIm-TFSI is due to the additional TFSI ${ }^{-}$anions, which are difficult to thermally decompose due to degradation via sulfur dioxide release instead of dealkylation or proton 
transfer.[46] Also, no weight loss was observed below $100^{\circ} \mathrm{C}$, indicating that these PILBCPs are highly hydrophobic and do not appreciably absorb moisture.
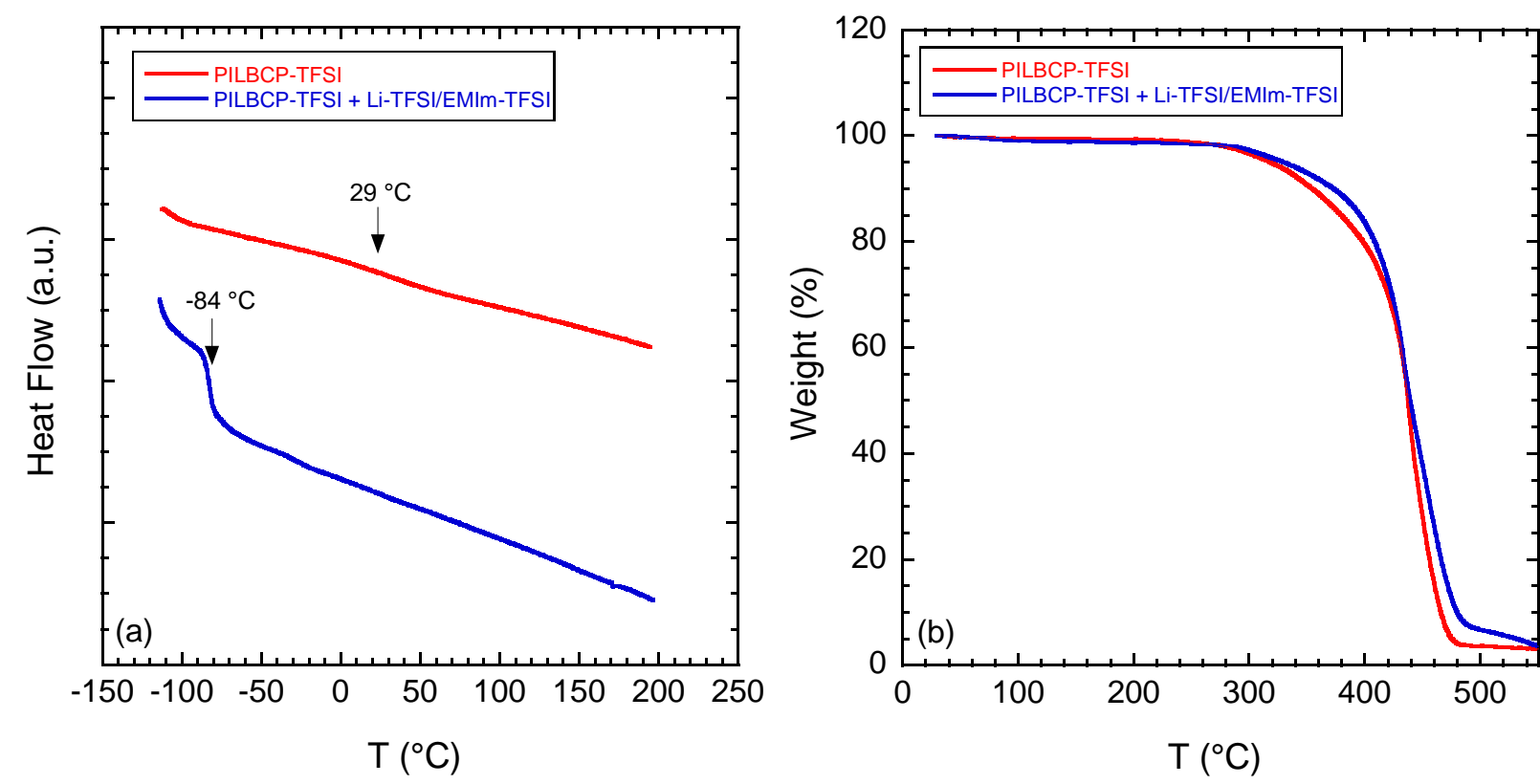

Figure 4. (a) DSC and (b) TGA thermograms of PILBCP-TFSI (red) and PILBCP-TFSI + LiTFSI/EMIm-TFSI (blue).

\subsection{Ion Conductivity}

Figure 5 shows the temperature-dependent $\left(25\right.$ to $\left.105{ }^{\circ} \mathrm{C}\right)$ ionic conductivity under dry conditions (in argon glove box) for PILBCP-TFSI, PILBCP-TFSI + Li-TFSI/EMIm-TFSI, and Li-TFSI/EMIm-TFSI. The ionic conductivity of Li-TFSI/EMIm-TFSI is shown as a control reference and has similar values as reported in literature.[35] As expected, the ionic conductivity of PILBCP-TFSI increased by 1.5 orders of magnitude with increasing temperature from values on the order of $0.3 \mu \mathrm{S} \mathrm{cm}{ }^{-1}$ at $25^{\circ} \mathrm{C}$ to values higher than $1 \mu \mathrm{S} \mathrm{cm}^{-1}$ at $105^{\circ} \mathrm{C}$. The temperaturedependent ionic conductivity in PILBCP-TFSI is dictated by the segmental dynamics of the polymer chains or polymer $T_{\mathrm{g}}$ (i.e., Volgel-Fulcher-Tammann (VFT) behavior with temperature). Note the ion conductivity of PILBCP-TFSI is orders of magnitude lower than the IL, e.g., 9.9 mS 
$\mathrm{cm}^{-1}$ at $25{ }^{\circ} \mathrm{C}$ for 1-butyl-3-methylimidazolium bis(trifluoromethane)sulfonimide (BMImTFSI).[47] In contrast to the IL, PILBCP-TFSI is a single ion conductor, where the TFSI $^{-}$ counter anion is the only mobile ion (the imidazolium cation is covalently attached to the polymer) and the movement of the $\mathrm{TFSI}^{-}$anion is restricted by the polymer chain dynamics of PILBCP-TFSI, thereby decreasing the ion conductivity compared to the IL, where both anion and cation are highly mobile.

The addition of Li-TFSI/EMIm-TFSI to PILBCP-TFSI increases the conductivity by 3.5 orders of magnitude at room temperature $\left(25^{\circ} \mathrm{C}\right)$ and 3 orders of magnitude at a higher temperature $\left(105^{\circ} \mathrm{C}\right)$ compared to PILBCP-TFSI. The increased conductivity is due to two main factors: (1) additional free ions (increased mobile ion concentration) and plasticization (depressed $T_{\mathrm{g}}$; see Figure 4a). The ion conductivity of PILBCP-TFSI + Li-TFSI/EMIm-TFSI increases from values on the order of 1 to $10 \mathrm{mS} \mathrm{cm}{ }^{-1}$ with increasing temperature from $25^{\circ} \mathrm{C}$ to $105^{\circ} \mathrm{C}$.

Interestingly, the conductivity of PILBCP-TFSI + Li-TFSI/EMIm-TFSI is similar to salt/ionic liquid mixture (Li-TFSI/EMIm-TFSI) with less than half an order of magnitude difference at high temperatures $\left(105{ }^{\circ} \mathrm{C}\right)$. It is known that solid-state polymer electrolytes should possess conductivities approaching or beyond $1 \mathrm{mS} \mathrm{cm}^{-1}$ at ambient temperature in order to compete with current lithium-ion batteries with liquid electrolytes.[5] The high conductivity $\left(>1 \mathrm{mS} \mathrm{cm}^{-1}\right)$ of the solid-state PILBCP-TFSI + Li-TFSI/EMIm-TFSI film at room temperature $\left(25^{\circ} \mathrm{C}\right)$ is promising for application to lithium-ion batteries. 


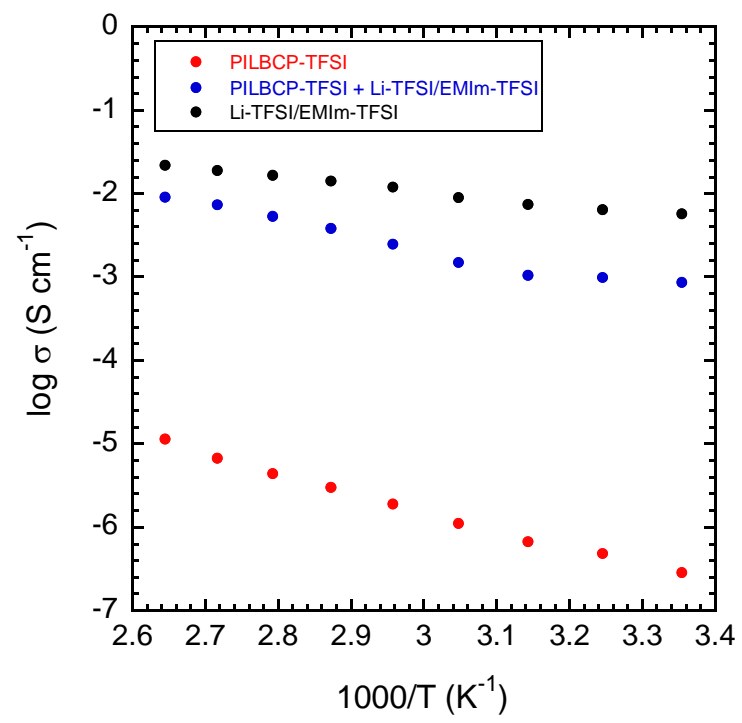

Figure 5. Temperature-dependent dry ionic conductivity of PILBCP-TFSI (red), PILBCP-TFSI + Li-TFSI/EMIm-TFSI (blue), and Li-TFSI/EMIm-TFSI (black).

\subsection{Morphology}

Figure 6a shows SAXS data for PILBCP-TFSI and PILBCP-TFSI + Li-TFSI/EMIm-TFSI under vacuum at room temperature. The SAXS profile of PILBCP-TFSI has two well-defined scattering peaks (at $q^{*}$ and $2 q^{*}$ ) indicative of microphase separation; the absence of higher order peaks suggests a lack of significant long-range order. A Bragg spacing $\left(d=2 \pi / q^{*}\right)$ of $26.7 \mathrm{~nm}$ for PILBCP-TFSI was determined from the SAXS data. The SAXS profile of PILBCP-TFSI + Li-TFSI/EMIm-TFSI only has a single broad primary scattering peak $\left(q^{*}\right)$ indicative of weak microphase separation; the absence of higher order peaks also suggests a lack of long-range order (Bragg spacing of $36.0 \mathrm{~nm}$ ). The addition of Li-TFSI/EMIm-TFSI to PILBCP-TFSI increases the Bragg spacing by almost $10 \mathrm{~nm}$ higher than PILBCP-TFSI and disrupts any possible long-range order and introduces electron density fluctuations over a range of length scales. The weakly microphase-separated morphology with no long-range order in the PILBCPTFSI + Li-TFSI/EMIm-TFSI sample evidenced by SAXS was confirmed with electron microscopy as shown in Figure 6b. The SAXS and TEM data showing that the samples are a 
microphase separated in these samples is important since previous results on PIL block copolymers show higher conductivity in samples with microphase separated morphologies compared to samples with the same chemistry without microphase separated morphologies.[10] The relatively high ionic conductivity of PILBCP-TFSI + Li-TFSI/EMIm-TFSI $\left(>1 \mathrm{mS} \mathrm{cm}^{-1}\right.$ at $25^{\circ} \mathrm{C}$ ) with block copolymer design providing mechanical strong free-standing films (see Figure 1b) allows for its use as a solid-state electrolyte and separator in a lithium-ion battery.
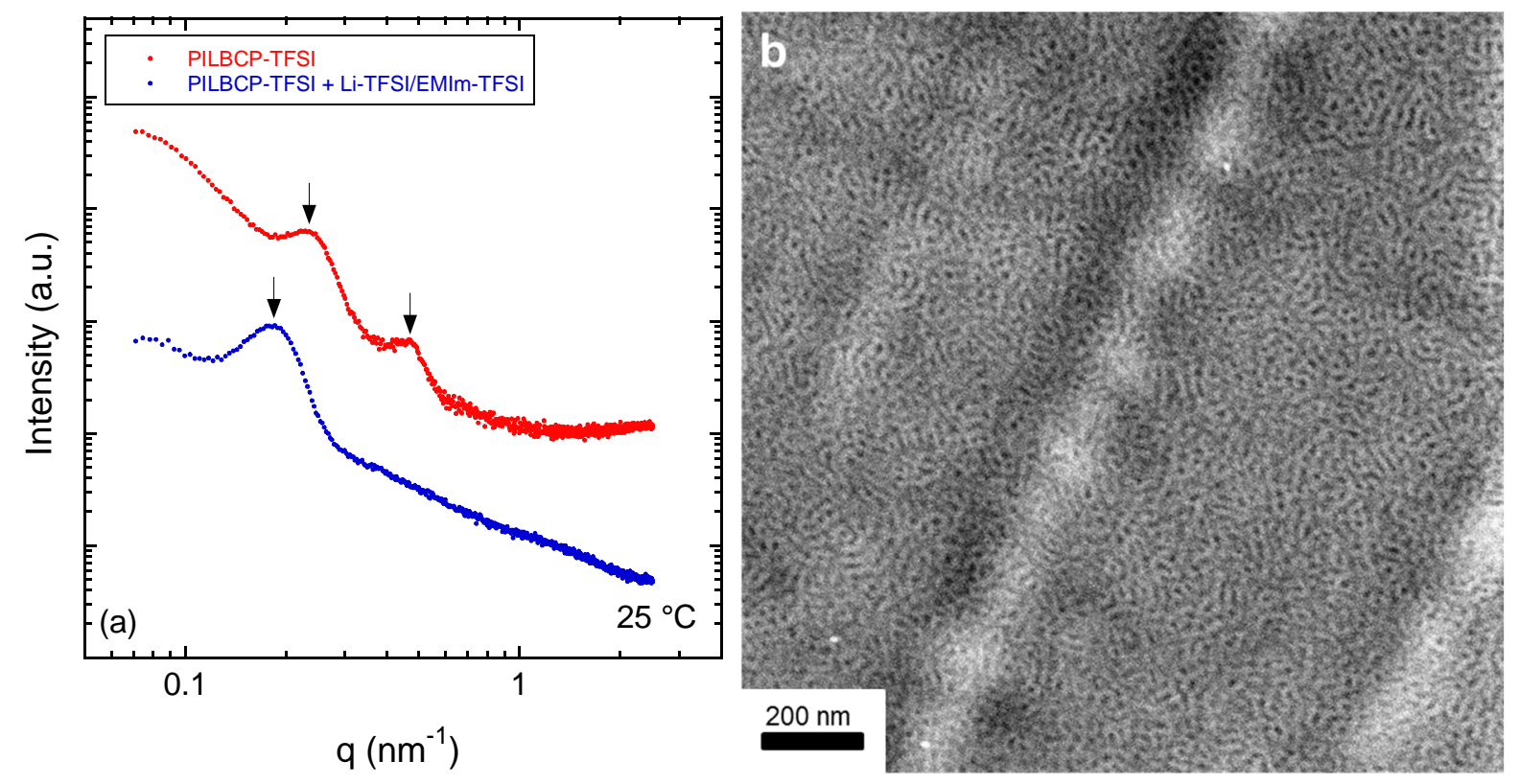

Figure 6. (a) Small-angle X-ray scattering profiles of PILBCP-TFSI (red) and PILBCP-TFSI + Li-TFSI/EMIm-TFSI (blue) and (b) electron microscopy images of PILBCP-TFSI + LiTFSI/EMIm-TFSI at room temperature under vacuum. HAADF STEM; sample unstained; light regions correspond to PIL domains. SAXS data collected at room temperature under vacuum. Arrows indicate peak positions. Data are vertically offset for clarity.

\subsection{Electrochemical stability}

The electrochemical stability window was measured by linear voltammetry with a platinum foil working electrode, PILBCP-TFSI + Li-TFSI/EMIm-TFSI film as the electrolyte and separator, and silver foil counter electrode at a scan rate of $5 \mathrm{mV} \mathrm{s}^{-1}$ (Figure 7). The results show 
that the PILBCP-TFSI + Li-TFSI/EMIm-TFSI film has a potential stability window of approximately $2.7 \mathrm{~V}$. The cathodic limit of $1.7 \mathrm{~V}$ versus $\mathrm{Li} / \mathrm{Li}^{+}$was observed, which does not allow the use of metallic lithium or carbon as the anode material. The cathodic limit may be a result of cation reduction of the three acidic protons on the imidazolium ring, especially the proton on the $\mathrm{C} 2$ position of the imidazolium ring, which has been previously reported, but not confirmed in this study.[48] It is important to note that the cathodic limit of $1.7 \mathrm{~V}$ for the PILBCP-TFSI + Li-TFSI/EMIm-TFSI film is higher than the cathodic limit of $1.0 \mathrm{~V}$ in pure EMIm-TFSI liquid.[35] The addition of polymeric ionic liquid with covalently attached imidazolium and lithium salt appears to improve the electrochemical stability of the ionic liquid alone (i.e., a smaller fraction of freely diffusing imidazolium cations). Figure 7 shows that the anodic decomposition begins at $4.4 \mathrm{~V}$ versus $\mathrm{Li} / \mathrm{Li}^{+}$and gradually increases to $6.2 \mathrm{~V}$ versus $\mathrm{Li} / \mathrm{Li}^{+}$, where the total oxidation of the anion $\left(\mathrm{TFSI}^{-}\right)$may occur. Similar trends have been observed for $\mathrm{TFSI}^{-}$containing PILs were the anodic decomposition reaction rate increases with temperature, which decreases the voltage range of the oxidation onset.[15] The electrochemical stability of just the polymer PILBCP-TFSI without Li-TFSI/EMIm-TFSI could not be measured due to the relatively low conductivity even at $90{ }^{\circ} \mathrm{C}$ (see Figure 5). 


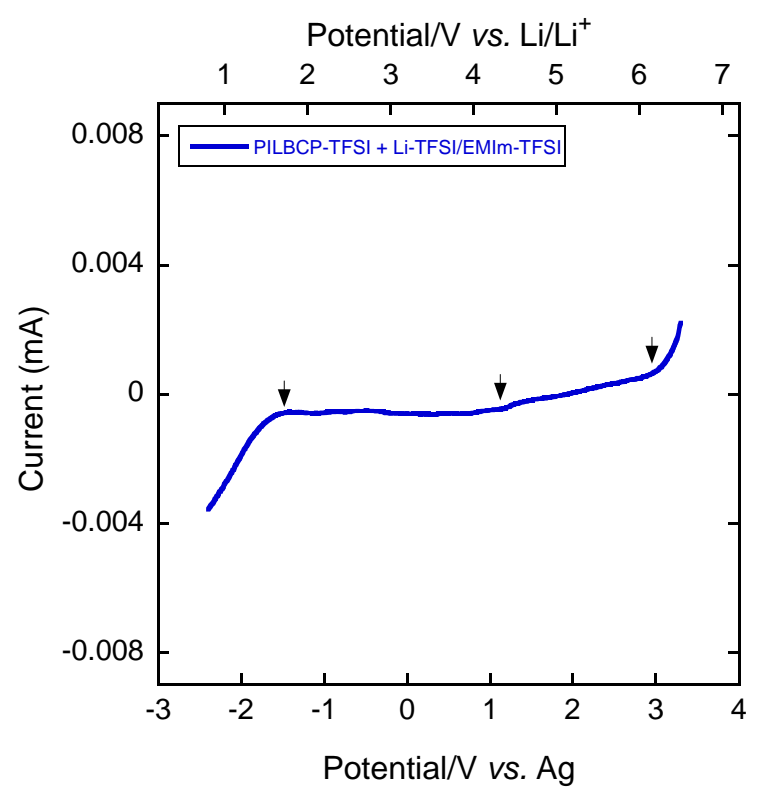

Figure 7. Linear voltammetry (electrochemical stability) of PILBCP-TFSI + Li-TFSI/EMImTFSI at room temperature at a scan rate of $5 \mathrm{mV} \mathrm{s}^{-1}$ with Pt working electrode and $\mathrm{Ag}$ counter and reference electrodes. Arrows indicate electrochemical stability limits.

\subsection{Lithium-ion battery performance}

Figure 8 shows the charge-discharge (C/D) performance of $\mathrm{Li}_{4} \mathrm{Ti}_{5} \mathrm{O}_{12} / \mathrm{PILBCP}-\mathrm{TFSI}+\mathrm{Li}$ TFSI/EMIm-TFSI/LiCoO 2 coin cell at room temperature. Lithium titanate $\left(\mathrm{Li}_{4} \mathrm{Ti}_{5} \mathrm{O}_{12}\right)$ was used as the negative electrode because its redox potential at approximately $1.5 \mathrm{~V}$ is within the stability window of PILBCP-TFSI. The $\mathrm{C} / \mathrm{D}$ cycles had a $\mathrm{C} / \mathrm{D}$ rate of $0.1 \mathrm{C}$ and a voltage window of 3.5 $\mathrm{V}$ to $4.0 \mathrm{~V}$ versus $\mathrm{Li} / \mathrm{Li}^{+}\left(2.0\right.$ to $2.5 \mathrm{~V}$ in a $\mathrm{Li}_{4} \mathrm{Ti}_{5} \mathrm{O}_{12} / \mathrm{LiCoO}_{2}$ cell) in order to minimize electrochemical degradation. The discharge capacity and the Coulombic efficiency of the battery were $97 \mathrm{mAh} \mathrm{g}^{-1}$ and 93\% in the first cycle, respectively. During the first 5 cycles, the discharge capacity increased gradually, possibly due to the penetration of Li-TFSI/EMIm-TFSI into the electrodes and the improved contact of the solid-state separator and electrodes.[16, 49] After this initial improvement, the cell delivered a maximum discharge capacity of $112 \mathrm{mAh} \mathrm{g}^{-1}$, approximately $70 \%$ of the theoretical capacity of $\mathrm{Li}_{4} \mathrm{Ti}_{5} \mathrm{O}_{12}\left(161 \mathrm{mAh} \mathrm{g}^{-1}\right)$ at $0.1 \mathrm{C}$. The cell 
maintained this maximum capacity for approximately 20 cycles. After 20 cycles, the capacity began to fade at a rate of $1.03 \mathrm{mAh} \mathrm{g}^{-1}$ per cycle. After 100 cycles, the discharge capacity of the battery was approximately $31 \mathrm{mAh} \mathrm{g}^{-1}$, which was $27 \%$ of the maximum capacity. However, the Coulombic efficiency maintained a value higher than $94 \%$ for all 100 cycles.

The relatively poor long term cycling of $\mathrm{Li}_{4} \mathrm{Ti}_{5} \mathrm{O}_{12} / \mathrm{PILBCP}-\mathrm{TFSI}+\mathrm{Li}-\mathrm{TFSI} / \mathrm{EMIm}$ TFSI/LiCoO 2 batteries may be due to the low electrochemical stability of PILBCP-TFSI + LiTFSI/EMIm-TFSI solid-state films (see Figure 7). Even though a relatively small voltage range was selected ( $3.5 \mathrm{~V}$ to $4.0 \mathrm{~V}$ versus $\mathrm{Li}_{2} / \mathrm{Li}^{+}$or 2.0 to $2.5 \mathrm{~V}$ in a $\mathrm{Li}_{4} \mathrm{Ti}_{5} \mathrm{O}_{12} / \mathrm{LiCoO}_{2}$ cell), electrochemical degradation may slowly decompose the film performance over time. The electrochemical degradation can be amplified in the coin cell due to the increased current compared to the electrochemical stability experiments. Choosing a different electrolyte and separator with a greater voltage stability window than EMIm-TFSI or a different PIL block may alleviate some of these stability issues.
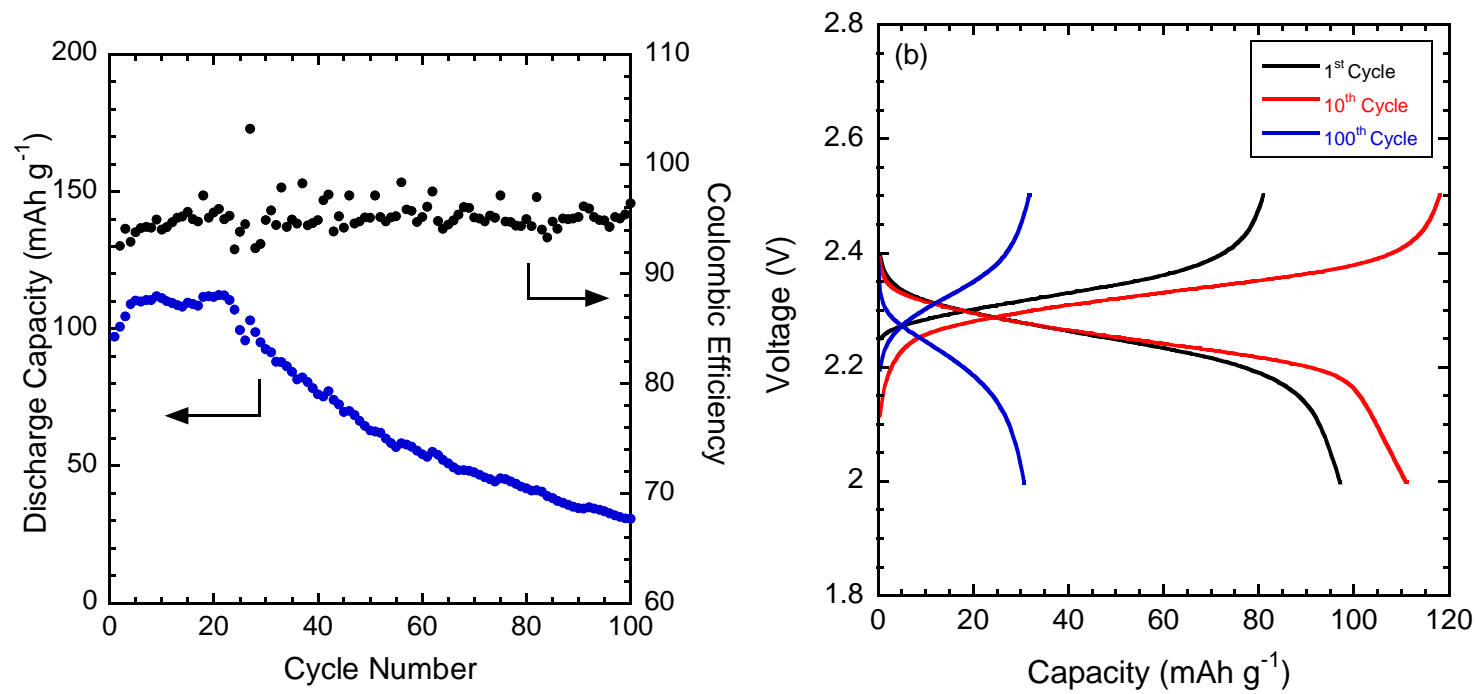

Figure 8. (a) Discharge capacity and Coulombic efficiency as a function of cycle number and (b) voltage versus capacity profile at select cycles at room temperature. Charge-discharge rate is $0.1 \mathrm{C}$. 


\section{Conclusion}

A new PIL diblock copolymer, PILBCP-TFSI, was synthesized via reverse addition fragmentation chain transfer polymerization followed by anion exchange metathesis. Robust free-standing solid polymer films were produced with Li-TFSI/EMIm-TFSI imbibed within the films to both plasticize to improve ion conductivity and as a source of lithium ions. The resulting high ionic conductivity $\left(>1 \mathrm{mS} \mathrm{cm}^{-1}\right)$ at room temperature $\left(25^{\circ} \mathrm{C}\right)$ for the PILBCP-TFSI + LiTFSI/EMIm-TFSI films allow for its use as a solid-state electrolyte and separator in lithium ion batteries. The electrochemical stability of PILBCP-TFSI + Li-TFSI/EMIm-TFSI was determined to have a potential window of $2.7 \mathrm{~V}$ with a cathodic limit of $1.7 \mathrm{~V}$ versus $\mathrm{Li} / \mathrm{Li}^{+}$and an anodic limit of $4.4 \mathrm{~V}$ versus $\mathrm{Li} / \mathrm{Li}^{+}$. The application of PILBCP-TFSI + Li-TFSI/EMIm-TFSI as a solidstate electrolyte and separator in lithium ion coin cells was tested using lithium titanate $\left(\mathrm{Li}_{4} \mathrm{Ti}_{5} \mathrm{O}_{12}\right)$ anodes and lithium cobalt oxide $\left(\mathrm{LiCoO}_{2}\right)$ cathodes. A maximum capacity of 112 $\mathrm{mAh} \mathrm{g}^{-1}$ was achieved for approximately 20 cycles before a capacity fade at a rate of $1.03 \mathrm{mAh}$ $\mathrm{g}^{-1}$ per cycle was observed. The battery maintained a Coulombic efficiency higher than $94 \%$ for all 100 cycles. The relativity small voltage window of $2.7 \mathrm{~V}$ is a possible reason for the capacity fade where electrochemical degradation could cause slow failure in the battery. However, to the authors' knowledge, this is the first report of a PILBCP used as solid-state electrolyte and separator in a lithium ion battery with performance data, and therefore this report shows the feasibility and functionality of PILBCPs as solid-state electrolytes and separators in lithium-ion batteries at room temperature. Thus, with the further improvement of the electrochemical stability of PILBCPs, there is a promising outlook for their use as solid-state electrolytes and separators in lithium-ion batteries. 


\section{Acknowledgements}

This work is supported in part by the U.S. Army Research Office under grant no. W911NF-140310. A.M.S. was supported by the Postgraduate Research Participation Program at the US Army Research Laboratory, administered by the Oak Ridge Institute of Science and Education through an interagency agreement between the US Department of Energy and Army Research Laboratory (Contract ORISE1120-1120-99). Special thanks to Bryan Byles in the Drexel University materials engineering department for assistance with fabricating the coin cell anodes.

\section{References}

[1] J.B. Goodenough, Y. Kim, Chem. Mat., 22 (2010) 587-603.

[2] J.M. Tarascon, M. Armand, Nature, 414 (2001) 359-367.

[3] A.S. Arico, P. Bruce, B. Scrosati, J.M. Tarascon, W. Van Schalkwijk, Nature Materials, 4 (2005) 366-377.

[4] B. Scrosati, J. Garche, Journal of Power Sources, 195 (2010) 2419-2430.

[5] J.Y. Song, Y.Y. Wang, C.C. Wan, J Power Sources, 77 (1999) 183-197.

[6] M. Jahan, Z.L. Liu, K.P. Loh, Adv Funct Mater, 23 (2013) 5363-5372.

[7] J. Wang, X. He, H. Zhu, D. Chen, RSC Advances, 5 (2015) 43581-43588.

[8] K.M. Meek, S. Sharick, Y. Ye, K.I. Winey, Y.A. Elabd, Macromolecules, 48 (2015) 48504862.

[9] Y. Ye, S. Sharick, E.M. Davis, K.I. Winey, Y.A. Elabd, ACS Macro Letters, 2 (2013) 575580.

[10] Y. Ye, J.-H. Choi, K.I. Winey, Y.A. Elabd, Macromolecules, 45 (2012) 7027-7035.

[11] K.M. Meek, Y.A. Elabd, Journal of Materials Chemistry A, 3 (2015) 24187-24194.

[12] M. Galiński, A. Lewandowski, I. Stępniak, Electrochim. Acta, 51 (2006) 5567-5580.

[13] H. Sakaebe, H. Matsumoto, Electrochemistry Communications, 5 (2003) 594-598.

[14] A. Lewandowski, A. Swiderska-Mocek, Journal of Power Sources, 194 (2009) 601-609.

[15] M. Li, L. Yang, S. Fang, S. Dong, S.-i. Hirano, K. Tachibana, Polymer International, 61 (2012) 259-264.

[16] M. Li, L. Yang, S. Fang, S. Dong, S.-i. Hirano, K. Tachibana, Journal of Power Sources, 196 (2011) 8662-8668.

[17] G.B. Appetecchi, G.T. Kim, M. Montanino, M. Carewska, R. Marcilla, D. Mecerreyes, I. De Meatza, Journal of Power Sources, 195 (2010) 3668-3675.

[18] T. Sato, S. Marukane, T. Narutomi, T. Akao, Journal of Power Sources, 164 (2007) 390396.

[19] P.-L. Kuo, C.-H. Tsao, C.-H. Hsu, S.-T. Chen, H.-M. Hsu, Journal of Membrane Science, 499 (2016) 462-469.

[20] P.E. Trapa, B. Huang, Y.-Y. Won, D.R. Sadoway, A.M. Mayes, Electrochemical and solidstate letters, 5 (2002) A85-A88. 
[21] P.P. Soo, B. Huang, Y.I. Jang, Y.M. Chiang, D.R. Sadoway, A.M. Mayes, Journal of The Electrochemical Society, 146 (1999) 32-37.

[22] E.D. Gomez, A. Panday, E.H. Feng, V. Chen, G.M. Stone, A.M. Minor, C. Kisielowski, K.H. Downing, O. Borodin, G.D. Smith, N.P. Balsara, Nano Letters, 9 (2009) 1212-1216.

[23] M. Singh, O. Odusanya, G.M. Wilmes, H.B. Eitouni, E.D. Gomez, A.J. Patel, V.L. Chen, M.J. Park, P. Fragouli, H. Iatrou, N. Hadjichristidis, D. Cookson, N.P. Balsara, Macromolecules, 40 (2007) 4578-4585.

[24] A. Panday, S. Mullin, E.D. Gomez, N. Wanakule, V.L. Chen, A. Hexemer, J. Pople, N.P. Balsara, Macromolecules, 42 (2009) 4632-4637.

[25] R. Bouchet, S. Maria, R. Meziane, A. Aboulaich, L. Lienafa, J.-P. Bonnet, T.N.T. Phan, D. Bertin, D. Gigmes, D. Devaux, R. Denoyel, M. Armand, Nat Mater, 12 (2013) 452-457.

[26] L. Gwee, J.-H. Choi, K.I. Winey, Y.A. Elabd, Polymer, 51 (2010) 5516-5524.

[27] R.L. Weber, Y. Ye, A.L. Schmitt, S.M. Banik, Y.A. Elabd, M.K. Mahanthappa, Macromolecules, 44 (2011) 5727-5735.

[28] L.D. McIntosh, T. Kubo, T.P. Lodge, Macromolecules, 47 (2014) 1090-1098.

[29] J.-H. Choi, Y. Ye, Y.A. Elabd, K.I. Winey, Macromolecules, 46 (2013) 5290-5300.

[30] P.M. Simone, T.P. Lodge, ACS Applied Materials \& Interfaces, 1 (2009) 2812-2820.

[31] M.D. Green, J.-H. Choi, K.I. Winey, T.E. Long, Macromolecules, 45 (2012) 4749-4757.

[32] J.R. Nykaza, Y. Ye, Y.A. Elabd, Polymer, 55 (2014) 3360-3369.

[33] J.R. Nykaza, R. Benjamin, K.M. Meek, Y.A. Elabd, Chemical Engineering Science Submitted.

[34] S. Cheng, D.M. Smith, C.Y. Li, Macromolecules, 48 (2015) 4503-4510.

[35] B. Garcia, S. Lavallée, G. Perron, C. Michot, M. Armand, Electrochim. Acta, 49 (2004) 4583-4588.

[36] T.C. Huang, H. Toraya, T.N. Blanton, Y. Wu, Journal of Applied Crystallography, 26 (1993) 180-184.

[37] F. Zhang, J. Ilavsky, G.G. Long, J.P.G. Quintana, A.J. Allen, P.R. Jemian, Metallurgical and Materials Transactions A, 41 (2009) 1151-1158.

[38] J. Ilavsky, P.R. Jemian, Journal of Applied Crystallography, 42 (2009) 347-353.

[39] H. Chen, J.-H. Choi, D. Salas-de la Cruz, K.I. Winey, Y.A. Elabd, Macromolecules, 42 (2009) 4809-4816.

[40] T. Seki, J.-D. Grunwaldt, A. Baiker, The Journal of Physical Chemistry B, 113 (2009) 114122.

[41] J. Kiefer, J. Fries, A. Leipertz, Appl. Spectrosc., 61 (2007) 1306-1311.

[42] S. Zhang, N. Sun, X. He, X. Lu, X. Zhang, Journal of physical and chemical reference data, 35 (2006) 1475-1517.

[43] M.A.B.H. Susan, T. Kaneko, A. Noda, M. Watanabe, J. Am. Chem. Soc., 127 (2005) 49764983.

[44] K.A. Page, K.M. Cable, R.B. Moore, Macromolecules, 38 (2005) 6472-6484.

[45] T.C. Chang, Y.T. Wang, Y.S. Hong, H.B. Chen, J.C. Yang, Polymer Degradation and Stability, 69 (2000) 317-322.

[46] A. Chowdhury, S.T. Thynell, Thermochimica Acta, 443 (2006) 159-172.

[47] A. Fernicola, B. Scrosati, H. Ohno, Ionics, 12 (2006) 95-102.

[48] P. Bonhôte, A.-P. Dias, N. Papageorgiou, K. Kalyanasundaram, M. Grätzel, Inorganic Chemistry, 35 (1996) 1168-1178. 
[49] J.-H. Shin, W.A. Henderson, S. Passerini, Journal of The Electrochemical Society, 152 (2005) A978-A983. 